\title{
Distribución y movimiento del colesterol en la membrana de eritrocito de pacientes con hipertensión esencial
}

\author{
Por F. J. G. Muriana1, J. Villar² y V. Ruiz-Gutiérrez'
}

1. Instituto de la Grasa, Consejo Superior de Investigaciones Científicas (C.S.I.C.). 2. Unidad de Hispertensión y Lípidos, Servicio de Medicina Interna, Hospital Universitario Virgen del Rocío, Sevilla

\section{RESUMEN}

Distribución y movimiento del colesterol en la membrana de eritrocito de pacientes con hipertensión esencial.

El presente estudio se llevó a cabo con 36 personas que se ofrecieron voluntarias, de las cuales 12 eran sujetos sanos, 12 pacientes hipertensos normocolesterolémicos y 12 pacientes hipertensos hipercolesterolémicos. Mediante punción en la vena antecubital, se recogieron muestras de sangre en citrato sódico al $0,38 \%$. La distribución del colesterol y su velocidad de transporte en la membrana de eritrocito se midieron según la técnica de la colesterol oxidasa. La medida de la velocidad máxima del contratransporte $\mathrm{Na}^{+}-\mathrm{Li}{ }^{+}$en eritrocito se efectuó según el eflujo de $\mathrm{Li}^{+}$en presencia o ausencia de $\mathrm{Na}^{+}$. El estudio estadístico se determinó según el análisis de varianza (ANOVA) para datos pareados con distribución normal. Para las correlaciones se empleó el test de regresión lineal de Pearson.

Los resultados indican que existe una distribución asimétrica del colesterol en la membrana de eritrocito humano (más colesterol en la monocapa interna que en la externa), aunque la monocapa interna del eritrocito de pacientes hipertensos es aún más rica en colesterol que la de sujetos sanos. Esta alteración es concomitante con una reducción de la velocidad de transporte del colesterol en la bicapa lipídica del eritrocito, que contribuye a la asimetría transmembrana y lateral del propio colesterol. Estos parámetros se correlacionan con la actividad en el eritrocito del contratransporte $\mathrm{Na}^{+}-\mathrm{Li}^{+}$, considerado como un indicador genético de la hipertensión esencial.

Puede afirmarse que la distribución del colesterol y su velocidad de transporte entre monocapas pueden desempeñar un papel específico en el proceso hipertensivo. Y, por extensión, en otras enfermedades asociadas con alteraciones en el metabolismo lipídico.

PALABRAS-CLAVE: Colesterol (distribución) - Colesterol (movimiento) - Hipertensión esencial - Membrana de eritrocito humano.

\section{SUMMARY}

Distribution and transbilayer movement of membrane cholesterol in erythrocyte of patients with essential hypertension.

The participants were 12 healthy subjects, 12 normocholesterolaemic hypertensive and 12 hypercholesterolaemic hypertensive patients. Venous blood samples were collected in

Trabajo ganador del VIII Premio "Dr. López Laguna» Sociedad Andaluza de Medicina Interna.
$0.38 \%$ sodium citrate. Erythrocyte membrane cholesterol distribution and transbilayer movement were measured according to the continuous cholesterol oxidase treatment. Erythrocyte $\mathrm{Na}^{+}-\mathrm{Li}^{+}$ countertransport activity was determined by measurements of $\mathrm{Li}^{+}$ efflux in the presence or absence of $\mathrm{Na}^{+}$. The statistical analysis was conducted for significance by using ANOVA for paired data and correlations were carried out by linear regression analysis using Pearson's correlation coefficient.

Our findings are consistent with the presence of cholesterolrich domains randomly distributed in the human erythrocyte. Cholesterol appeared to be similarly enriched in the cytofacial monolayer but the size of such structural cholesterol pool was greater in erythrocytes of hypertensive patients than in those of healthy subjetcs. There was also a decrease in the movement rate of erythrocyte membrane cholesterol, which contributed to keep impaired the asymmetric distribution of cholesterol in hypertensive patients. In addition, there was a strong correlation between the half-time for membrane cholesterol distribution or transbilayer movement and erythrocyte $\mathrm{Na}^{+}-\mathrm{Li}^{+}$countertransport activity, a well known marker of inherited predisposition to essential hypertension.

Our data indicate that the steady-state distribution of membrane cholesterol and cell cholesterol exchange may be intimately linked to the etiology of essential hypertension, and to other diseases which are associated to alterations in the lipid metabolism.

KEY-WORDS: Cholesterol (distribution) - Cholesterol (transbilayer movement) - Essential hypertension - Membrane of human erythrocyte.

\section{PRÓLOGO}

El presente trabajo constituye el estudio preliminar del efecto de dietas enriquecidas con aceite de oliva virgen sobre distintos parámetros relacionados con la hipertensión esencial humana, como principal factor de riesgo que afecta a la Patología Cardiovascular. La estrategia experimental consiste en la búsqueda de nuevos caminos sobre las alteraciones estructurales o cinéticas en las membranas biológicas que puedan contribuir al mejor entendimiento del metabolismo lipídico frente a la ingesta de alimentos ricos en grasas monoinsaturadas. El objetivo final es determinar si con la dieta (aceite de oliva virgen) se pueden normalizar aquellas modificaciones y definir los mecanismos celulares o moleculares que inducen la re-configuración de las membranas tras una dieta rica en ácidos grasos monoinsaturados. 
En su conjunto, estos estudios pretenden contribuir a un mejor conocimiento del aceite de oliva virgen y su normalización basada en la composición de componentes con una actividad biológica de interés. De este modo, se puede mejorar la calidad del aceite de oliva virgen mediante la selección de variedades enriquecidas en alguno(s) de estos componentes. Ello proporcionaría nuevas expectativas para un mayor consumo del aceite de oliva virgen, y un estímulo para el sector productivo e industrial.

\section{INTRODUCCIÓN}

Distintos componentes de membrana, como son los sistemas de transporte del ión sodio (Figura 1), presentan una función anormal en los eritrocitos de pacientes con hipertensión esencial: aumento de la actividad del intercambiador $\mathrm{Na}^{+-} \mathrm{H}^{+}$(Canessa et al., 1991) y del contratransporte $\mathrm{Na}^{+-} \mathrm{Li}^{+}$(Canessa et al., 1980; Muriana et al., 1996a), y disminución de la actividad enzimática ATPasa Na+-K+ (Poston, 1987) y del cotransporte $\mathrm{Na}^{+-} \mathrm{K}+$ (Saitta et al., 1988). Estas anomalías en el metabolismo iónico celular conducen a un incremento de la concentración intracelular del sodio, cuya difusión pasiva también está aumentada en la hipertensión esencial (Garay et al., 1981). En su conjunto, unido a la mayor sensibilidad de los receptores adrenérgicos $a_{2}$ plaquetarios (Insel y Motulsky, 1984; Postnov, 1990), se produciría un aumento del tono vascular (por aumento del calcio intracelular) y con ello una elevación de las cifras de tensión arterial (Cooper et al., 1987; David-Dufilho et al., 1992).

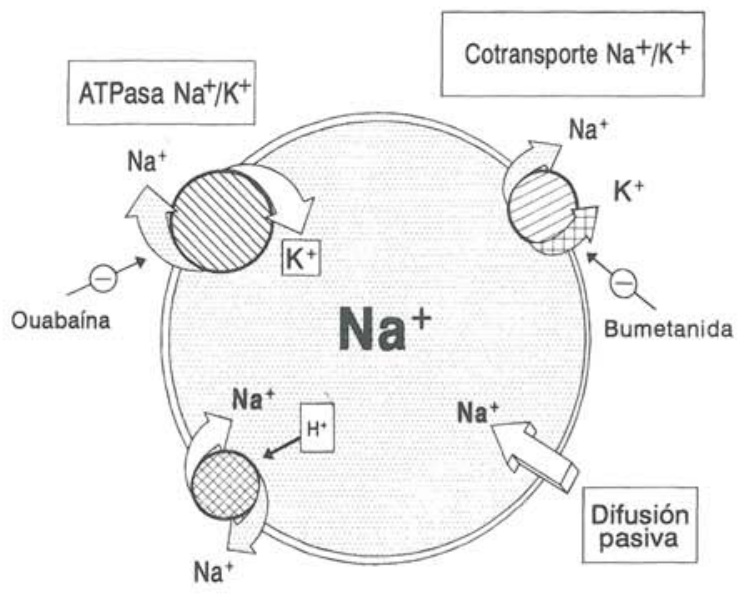

Contratransporte $\mathrm{Na}^{+} / \mathrm{Li}^{+}$

La ouabaína y bumetanida actúan como inhibidores de la actividad ATPasa $\mathrm{Na}^{+} / \mathrm{K}^{+}$y del cotransporte $\mathrm{Na}^{+} / \mathrm{K}^{+}$, respectivamente

Figura 1

Ilustración de los distintos sistemas de transporte del ión $\mathrm{Na}$ en eritrocito humano
Estas proteínas reguladoras del potencial eléctrico de membrana y del gradiente iónico intra-/extracelular se encuentran insertadas en la bicapa lipídica, que constituye la base estructural de toda membrana biológica (Figura 2). Parece ser que los lípidos de la membrana celular modulan la actividad de tales proteínas, si bien el mecanismo de esta interacción aún se desconoce. Así, las actividades del contratransporte $\mathrm{Na}^{+-} \mathrm{Li}^{+}$, del cotransporte $\mathrm{Na}^{+-} \mathrm{K}+$ y de la ATPasa $\mathrm{Na}^{+-}$ $\mathrm{K}^{+}$se correlacionan negativamente con el contenido de colesterol y fosfolípidos de la membrana de eritrocitos de humanos sanos (Lijnen et al., 1992; Lijnen et al., 1994).
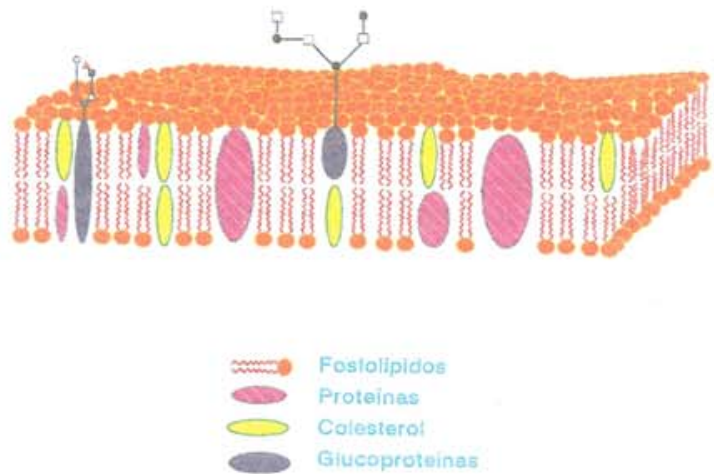

Obsérvese la disposición de la bicapa lipídica formada esencialmente por fosfolípidos

Figura 2

llustración de un modelo de membrana celular

Las actividades del intercambiador $\mathrm{Na}^{+-} \mathrm{H}^{+}$en linfocitos y del cotransporte $\mathrm{Na}^{+-} \mathrm{K}+$ en eritrocitos también se correlacionan de manera positiva con las concentraciones plasmáticas de colesterol y triglicéridos, respectivamente (Carr et al., 1993; Lijnen et al., 1994), mientras que la actividad del contratransporte $\mathrm{Na}^{+-} \mathrm{Li}+$ se asocia al aumento plasmático tanto de colesterol, de triglicéridos, como de fosfolípidos (Carr et al., 1990; Lijnen et al., 1994). Este último sistema de transporte también es sensible a los niveles de insulina en sangre (Doria et al., 1991; Mattiason et al., 1991). Tal observación es de extrema importancia, puesto que en la hipertensión esencial humana generalmente coinciden las alteraciones del metabolismo lipídico con una resistencia a la insulina e hiperinsulinemia (Villar et al., 1994).

La composición de los lípidos plasmáticos (colesterol y fosfolípidos) también influyen sobre la fluidez de membrana, que se encuentra alterada en pacientes hipertensos. En efecto, estudios de polarización (anisotropia) de fluorescencia con eritrocitos y plaquetas de pacientes con hipertensión esencial demuestran un incremento de la microviscosidad (disminución de la 
fluidez) de sus membranas (Sandhagen et al., 1990; Dominiczak y Bohr, 1991; Ronquist et al., 1992). Más importante, la anisotropía de fluorescencia en linfocitos se correlaciona negativamente con la actividad del intercambiador $\mathrm{Na}^{+-} \mathrm{H}^{+}$(Carr et al., 1993), que interviene en la regulación del volumen y $\mathrm{pH}$ intracelular, de la respuesta humoral acusada por agentes vasoactivos, de la reabsorción renal de $\mathrm{Na}^{+}$, y de la proliferación y crecimiento celular. Esta interconexión entre microviscosidad y transportadores iónicos puede depender, en parte, del contenido y distribución del colesterol y esfingomielina en la bicapa lipídica, que constituyen los componentes físicos que confieren mayor o menor rigidez a la membrana que los sustenta (Schroeder et al., 1991a). Ambos, el esterol y el fosfolípido, tienen la particularidad de ser afines entre sí, es decir, el colesterol interacciona preferentemente con la esfingomielina y en menor grado con el resto de fosfolípidos (Barenholz, 1984).

Hasta ahora, todos los intentos de demostrar el mecanismo de acción mediante el cual los lípidos plasmáticos y de membrana pueden modular los sistemas de transporte iónico, y en particular el contratransporte $\mathrm{Na}^{+-} \mathrm{Li}+$ que se considera como el marcador genético de la hipertensión esencial (Canesa et al., 1980; Carr et al., 1993), han sido infructuosos. La mayoría de estos estudios se han basado en la modificación cuantitativa de los lípidos de membrana mediante intervenciones dietéticas en personas sanas, tratando de asociar tales modificaciones con el flujo iónico transmembrana (Heagerty et al., 1986; Pagnan et al., 1989; Mclver et al., 1990), pero sin establecer un vínculo causal concreto. La extensión de estas investigaciones en pacientes con hipertensión esencial demuestran que una dieta enriquecida con aceite de oliva (Corrocher et al., 1992; Muriana et al., 1996b) puede aumentar la actividad de la bomba $\mathrm{Na}^{+-}$ $\mathrm{K}^{+}$y cotransporte $\mathrm{Na}^{+-} \mathrm{K}^{+}$, y la permeabilidad pasiva por el $\mathrm{Na}^{+}$, así como reducir la actividad anormalmente alta del contratransporte $\mathrm{Na}^{+-} \mathrm{Li}^{+}$. Estos resultados son de suma importancia, por cuanto que constituyen una pieza clave para normalizar el tratamiento dietético como coadyuvante al tratamiento farmacológico de ésta y otras enfermedades asociadas con el metabolismo lipídico.

Sin embargo, la limitación de los estudios llevados a cabo hasta ahora radica en el concepto básico de membrana biológica, que se ha considerado simplemente como una estructura formada por lípidos y proteínas, sin organización. Nada más lejos de la realidad. En efecto, existen en la actualidad datos suficientes para afirmar que en las membranas biológicas coexisten dominios discretos de lípidos (Tocanne et al., 1989; Schroeder et al., 1991a; Liscum and Faust, 1994). La distribución asimétrica de los fosfolípidos ha sido ampliamente estudiada en la membrana de eritrocitos humanos, observándose que en la monocapa externa predominan la fosfatidilcolina y la esfingomielina, mientras que en la monocapa interna abundan los aminofosfolípidos como son la fosfatidiletanolamina y la fosfatidilserina (Figura 3). Estos dominios discretos de fosfolípidos en la bicapa lipídica se relacionan con procesos de difusibilidad a través de la membrana y con la microviscosidad de ésta (Devaux, 1988). El colesterol es, no obstante, el componente de la bicapa lipídica que reviste mayor interés. Al igual que ocurre con los fosfolípidos, el colesterol no se distribuye homogéneamente en las membranas biológicas y se reconocen tres tipos de dominios de colesterol en las células (Tabla 1). El transporte intervesicular, la actividad de proteínas citosólicas de transferencia de lípidos intracelular, o la actividad de proteinas unidas a membrana que transfieren esteroles son entre otros, los procesos que se relacionan con esta distribución asimétrica del colesterol (Schroeder et al., 1991a). En humanos, el colesterol se localiza preferentemente en la monocapa interna de las membranas (distribución asimétrica transmembrana), formando dominios ricos y dominios pobres en cada monocapa (distribución asimétrica lateral) (Schroeder et al., 1991b; Liscum and Faust, 1994; Muriana et al., 1994).
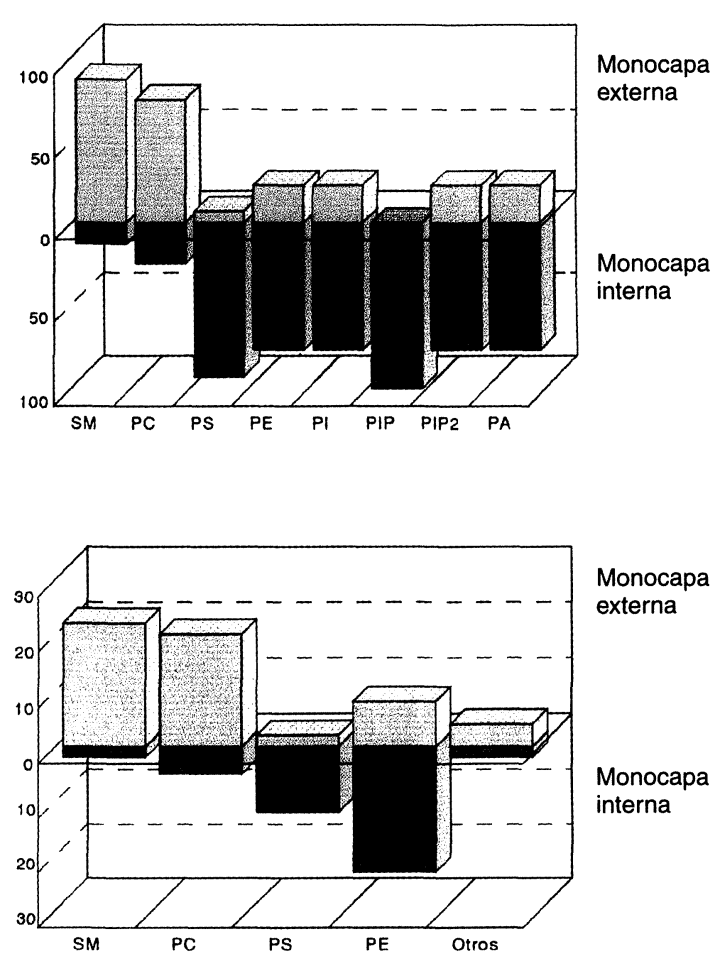

Los valores expresan el porcentaje de cada fosfolípido (gráfica superior) ó el porcentaje del total de fosfolipidos (gráfica inferior).

SM, esfingomielina; $P C$, fosfatidilcolina; $P S$, fosfatidilserina; $P E$, fosfatidiletanolamina; PI, fosfatidilinositol; PIP, fosfatidilinositol 4-fosfato; PIP2, fosfatidilinositol 4,5-difosfato; $\mathrm{PA}$, ácido fosfatídico.

Figura 3

Distribución asimétrica de los fosfolípidos en la membrana de eritrocito humano 
Tabla 1

Distribución asimétrica del colesterol en las células

\author{
- Intracelular \\ Membrana plasmática > microsomas > mitocondria

\section{- Transmembrana} \\ - Lateral (monocapa): dominios ricos y pobres
}

Esta distribución asimétrica del colesterol en membranas es muy sensible a la incorporación de ácidos grasos insaturados, a la presencia de esteroles oxidados, a la exposición crónica de etanol y a la expresión de proteínas citosólicas portadoras de esteroles (Schroeder et al., 1991a). La interpretación de esta localización física de múltiples dominios de colesterol es también dependiente de su velocidad de movimiento en la bicapa lipídica (Schroeder et al., 1991b; Liscum and Faust, 1994; Muriana et al., 1995).

El significado fisiológico de la distribución asimétrica del colesterol en membranas no se conoce, pero el hecho de que algunas proteínas se encuentren físicamente localizadas en dominios ricos de colesterol, en dominios pobres de colesterol, o incluso específicamente asociadas con el colesterol (Schroeder et al., 1991a), indica que tales dominios pudieran influir sobre la actividad o función de estas proteínas. Parece ser que el mecanismo de acción se basa en la capacidad del colesterol para promover la agregación (separación de fases) y subsiguiente activación del transportador iónico o cualquier otra proteína de membrana (Shouffani et al., 1990; Schroeder et al., 1991a). Tal hipótesis podría explicar la activación del contratransporte $\mathrm{Na}^{+-} \mathrm{Li}+$ que se produce en la hipertensión esencial, por cuanto que la modificación de la distribución asimétrica del colesterol puede formar parte de las anomalías patogénicas asociadas con la regulación de la presión arterial (Schroeder et al., 1991a; Engler et al., 1992; Corrocher et al., 1992; Rothblat et al., 1992; Straznicky et al., 1993; Ruiz-Gutiérrez et al., 1996). En este sentido, cabe considerar la distribución asimétrica del colesterol como el sustrato anatómico de las alteraciones de los transportadores de membrana.

Por lo tanto, el objeto de este estudio es determinar si la forma de distribuirse el colesterol y su velocidad de movimiento en la bicapa lipídica de eritrocito de pacientes con hipertensión esencial se relacionan con la etiología de la enfermedad. Nuestros resultados pueden abrir un nuevo horizonte para el tratamiento de la hipertensión basado en el control de la estructura y cinéticas de los dominios discretos de colesterol en las membranas celulares del árbol vascular. Este tipo de tratamiento puede ser farmacológico y/o dietético. En este último sentido, estudios preliminares en nuestro laboratorio han puesto de manifiesto que tras la ingesta de aceite de oliva se producen cambios en la composición lipídica de la membrana de eritrocito de sujetos sanos y pacientes hipertensos que se correlacionan con un efecto hipotensor. Además, tenemos datos para afirmar que el aceite de oliva activa mecanismos de homeostasis en la bicapa lipídica de las membranas cuando éstas se encuentran alteradas en el proceso hipertensivo. Es decir, es muy probable que la habilidad del aceite de oliva para reducir la tensión arterial sea debido a su capacidad para modular la distribución y el transporte del colesterol en las células.

\section{PACIENTES Y MÉTODOS}

El estudio se llevó a cabo con 12 pacientes hipertensos-normocolesterolémicos, 12 pacientes hipertensos-hipercolesterolémicos y 12 sujetos sanos. En los tres grupos, la mitad fueron hombres y la otra midad mujeres, con una media escasamente dispersa de 42 años y $70 \mathrm{Kg}$ de peso. El criterio de hipertensión fue una presión sistólica $\geq 140 \mathrm{~mm} \mathrm{Hg}$ y una presión diastólica $\geq 90 \mathrm{~mm} \mathrm{Hg}$ medidas, al menos, en tres ocasiones después de $10 \mathrm{~min}$ en posición supina (Tabla 2). El criterio de hipercolesterolemia fue una concentración en plasma de colesterol total $\geq 6,22 \mathrm{mmol} / \mathrm{L}$ y LDL-colesterol $\geq 4,14 \mathrm{mmol} / \mathrm{L}$ después de $12 \mathrm{~h}$ de ayuno (Tabla 3).

Tabla 2

Características de los participantes en este estudio

\begin{tabular}{|c|c|c|c|}
\hline Parámetro & $\begin{array}{l}\text { Sujetos } \\
\text { controles }\end{array}$ & $\begin{array}{l}\text { Pacientes hipertensos } \\
\text { normocolesterolémicos }\end{array}$ & $\begin{array}{l}\text { Pacientes hipertensos } \\
\text { hipercolesterolémicos }\end{array}$ \\
\hline Edad (años) & $54,2 \pm 3,7$ & $56,2 \pm 4,8$ & $56,8 \pm 3,5$ \\
\hline Indice de masa corporal $\left(\mathrm{kg} / \mathrm{m}^{2}\right)$ & $25,7 \pm 3,7$ & $24,5 \pm 1,3$ & $25,1 \pm 2,2$ \\
\hline \multicolumn{4}{|l|}{ Presión sanguínea: } \\
\hline Diastólica (mm Hg) & $71,8 \pm 4,0$ & $94,9 \pm 5,0^{\star \star \star}$ & $92,0 \pm 3,1^{\star \star \star}$ \\
\hline Sistólica $(\mathrm{mm} \mathrm{Hg})$ & $122,5 \pm 8,9$ & $161,2 \pm 14,4^{\star \star *}$ & $163,9 \pm 4,3^{\star \star \star}$ \\
\hline
\end{tabular}

Los valores expresan la media desviación estándar $(n=12)$

Valores significativamente diferentes del control: ${ }^{\star} P<0,1{ }^{\star \star} P<0,01^{\star \star \star} P<0,001$. 
Tabla 3

Concentración de los lípidos, lipoproteínas y apolipoproteínas (apo) en plasma de los participantes en este estudio

\begin{tabular}{|c|c|c|c|}
\hline Parámetro & $\begin{array}{l}\text { Sujetos } \\
\text { controles }\end{array}$ & $\begin{array}{l}\text { Pacientes hipertensos } \\
\text { normocolesterolémicos }\end{array}$ & $\begin{array}{l}\text { Pacientes hipertensos } \\
\text { hipercolesterolémicos }\end{array}$ \\
\hline Colesterol total (mmol/L) & $4,82 \pm 0,69$ & $4,83 \pm 0,97$ & $6,30 \pm 0,48^{\star \star \star}$ \\
\hline HDL-colesterol (mmol/L) & $1,26 \pm 0,23$ & $1,21 \pm 0,42$ & $1,19 \pm 0,42$ \\
\hline $\mathrm{HDL}_{2}$-colesterol (mmol/L) & $0,28 \pm 0,16$ & $0,22 \pm 0,11$ & $0,39 \pm 0,18$ \\
\hline $\mathrm{HDL}_{3}$-colesterol $(\mathrm{mmol} / \mathrm{L})$ & $0,96 \pm 0,19$ & $0,99 \pm 0,38$ & $0,79 \pm 0,25$ \\
\hline LDL-colesterol $(\mathrm{mmol} / \mathrm{L})$ & $3,43 \pm 0,48$ & $3,48 \pm 0,14$ & $4,41 \pm 0,32^{* * *}$ \\
\hline VLDL-colesterol (mmol/L) & $0,13 \pm 0,07$ & $0,14 \pm 0,05$ & $0,62 \pm 0,32^{\star \star \star}$ \\
\hline Fosfolípidos totales (mmol/L) & $63,92 \pm 9,98$ & $67,35 \pm 9,99$ & $88,04 \pm 5,03^{\star \star \star}$ \\
\hline HDL-fosfolípidos (mmol/L) & $31,91 \pm 5,96$ & $32,17 \pm 9,10$ & $34,40 \pm 9,99$ \\
\hline $\mathrm{HDL}_{2}$-fosfolípidos ( $\left.\mathrm{mmol} / \mathrm{L}\right)$ & $8,56 \pm 2,44$ & $4,85 \pm 1,81^{\star \star \star}$ & $11,63 \pm 5,31$ \\
\hline $\mathrm{HDL}_{3}$-fosfolípidos $(\mathrm{mmol} / \mathrm{L})$ & $22,98 \pm 3,43$ & $27,33 \pm 8,89$ & $22,77 \pm 8,09$ \\
\hline LDL-fosfolípidos (mmol/L) & $28,72 \pm 5,76$ & $31,65 \pm 7,95$ & $43,12 \pm 4,45^{\star \star \star}$ \\
\hline VLDL-fosfolípidos (mmol/L) & $3,22 \pm 1,55$ & $3,52 \pm 1,04$ & $10,52 \pm 6,41^{\star \star \star}$ \\
\hline Triglicéridos totales $(\mathrm{mmol} / \mathrm{L})$ & $0,85 \pm 0,25$ & $0,95 \pm 0,60$ & $2,27 \pm 0,66^{\star \star \star}$ \\
\hline HDL-triglicéridos (mmol/L) & $0,18 \pm 0,05$ & $0,16 \pm 0,05$ & $0,24 \pm 0,08$ \\
\hline LDL-triglicéridos (mmol/L) & $0,24 \pm 0,09$ & $0,30 \pm 0,15$ & $0,45 \pm 0,03^{\star \star \star}$ \\
\hline VLDL-triglicéridos (mmol/L) & $0,42 \pm 0,16$ & $0,48 \pm 0,21$ & $1,34 \pm 0,85^{\star \star \star}$ \\
\hline Apo A-I (g/L) & $1,60 \pm 0,23$ & $1,83 \pm 0,24$ & $1,76 \pm 0,17$ \\
\hline Apo B $(g / L)$ & $1,08 \pm 0,18$ & $1,05 \pm 0,08$ & $1,48 \pm 0,25^{\star \star \star}$ \\
\hline Colesterol total/HDL-colesterol & $3,81 \pm 0,88$ & $4,05 \pm 1,11$ & $5,32 \pm 1,09^{* *}$ \\
\hline LDL-colesterol/HDL-colesterol & $2,70 \pm 0,34$ & $2,85 \pm 0,61$ & $3,76 \pm 0,97^{\star *}$ \\
\hline
\end{tabular}

Los valores expresan la media \pm desviación estándar $(n=12)$

Valores significativamente diferentes del control: ${ }^{\star \star} P<0,01^{\star \star \star} P<0,001$.

Los experimentos sobre la distribución del colesterol y su velocidad de transporte transmembrana se efectuaron según el método de la colesterol oxidasa (Brasaemle et al., 1998; Muriana et al., 1994; Muriana et al., 1995). Brevemente, mediante punción venosa se obtuvo sangre en presencia de citrato sódico $0,38 \%$. Tras someterse la sangre venosa a centrifugación $(1750 \times \mathrm{g})$ durante $5 \mathrm{~min}$, a $4^{\circ} \mathrm{C}$, los eritrocitos se lavaron tres veces con solución amortiguadora salina $(\mathrm{NaCl} 145 \mathrm{mmol} / \mathrm{L}, \mathrm{KCl} 5 \mathrm{mmol} / \mathrm{L}$ y fosfato sódico $5 \mathrm{mmol} / \mathrm{L}, \mathrm{pH} 7,4$ ) y tres veces con solución amortiguadora de ensayo (sacarosa $310 \mathrm{mmol} / \mathrm{L}, \mathrm{MgSO}_{4}$ $1 \mathrm{mmol} / \mathrm{L}$ y fosfato sódico $5 \mathrm{mmol} / \mathrm{L}, \mathrm{pH} 7,4)$, donde se resuspendieron hasta un hematocrito del $3 \%$ (aproximadamente $50 \mu \mathrm{g}$ colesterol de eritrocito/ml de suspensión de células). En todas las experiencias se utilizaron eritrocitos obtenidos no más de $6 \mathrm{~h}$ después de la extracción sanguínea. Alícuotas $(3 \mathrm{~mL})$ de la suspensión de eritrocitos se incubaron durante $5 \mathrm{~min}$, a $4^{\circ} \mathrm{C}$, con $185 \times 10^{6} \mathrm{~Bq}$ de $\left[{ }^{3} \mathrm{H}\right]$-colesterol $\left(1.88 \times 10^{12}\right.$ $\mathrm{Bq} / \mathrm{mmol}$ ) en $50 \mu \mathrm{L}$ de etanol. Dependiendo del experimento, los eritrocitos marcados se preincubaron a $37^{\circ} \mathrm{C}$ (entre 0 y $100 \mathrm{~min}$ ) y entonces se trataron brevemente con colesterol oxidasa (Brevibacterium sp., 6
$\mathrm{U} / \mathrm{mL}$ ) durante $20 \mathrm{~s}$, o se preincubaron durante $15 \mathrm{~s}$ a $37^{\circ} \mathrm{C}$ y entonces se trataron de manera continua con la enzima (entre 0 y $25 \mathrm{~min}$ ). Se tomaron alícuotas que se extrajeron con una mezcla de cloroformometanol $(2: 1, \mathrm{v} / \mathrm{v})$ y en la fase orgánica se determinaron inmediatamente la masa y la radioactividad de colesterol y colestenona (resultado de la oxidación del colesterol).

Las masas de colesterol y colestenona se determinaron mediante cromatografía gaseosa, utilizando un cromatógrafo de gases Hewlett-Packard $5790 \mathrm{~A}$ equipado con un integrador (modelo 3390a; HewlettPackard Inc.). Las muestras orgánicas se evaporaron con una corriente continua de nitrógeno gaseoso, se redisolvieron en éter isopropílico frío $(15 \mu \mathrm{L})$, y se inyectaron en una columna Supelcoport $80 / 100$ (3\% OV-17; Teknokroma 14280C; Supelco Inc.), utilizando nitrógeno $(20 \mathrm{~cm} 3 / \mathrm{min})$ como gas portador. La temperatura de columna fue de $325^{\circ} \mathrm{C}$, y las temperaturas del inyector y detector de 350 y $360^{\circ} \mathrm{C}$, respectivamente. La masa de cada esterol se calculó mediante comparación del área de su pico cromatográfico con el área del pico correspondiente a concentraciones conocidas de estigmasta-4,22-dienona (patrón interno). 
Las radioactividades de colesterol y colestenona se determinaron mediante cromatrografía en capa fina. Las muestras orgánicas se evaporaron con una corriente continua de nitrógeno gaseoso, se redisolvieron en cloroformo $(20 \mu \mathrm{L})$, y se colocaron en placas de cromatrografía en capa fina de Silica-Gel 60. Los desarrollos se efectuaron en una mezcla de hexano:éter etílico:ácido acético (80:25:1, v/v/v). La radiación $B$ se detectó con la ayuda de un analizador lineal semi-automático Berthold, conectado a un ordenador Apple lle provisto con un software de trabajo individual. Las bandas radioactivas se rasparon de las placas, se colocaron en viales de centelleo y, tras añadir $10 \mathrm{~mL}$ de líquido de centelleo, se determinaron las dpm en un contandor Beckman (Beckman Instruments Inc.) convenientemente calibrado.

La medida de la velocidad máxima del contratransporte $\mathrm{Na}^{+-} \mathrm{Li}+$ se llevó a cabo según el método de Canessa et al. (1980). El flujo de $\mathrm{Na}^{+}$dependiente de este sistema se consideró como el componente de la salida neta de $\mathrm{Na}+$ que, siendo resistente a la ouabaína y a la bumetanida, era estimulado por $\mathrm{Li}^{+}$. Tras someterse la sangre venosa a centrifugación (1750 x g) durante $5 \mathrm{~min}, \mathrm{a} 4^{\circ} \mathrm{C}$, los eritrocitos se lavaron cuatro veces con una solución de $\mathrm{MgCl}_{2} 110 \mathrm{mmo} / \mathrm{L}$ y resuspendieron con una solución amortiguadora de sobrecarga de $\mathrm{Li}^{+}\left(\mathrm{Li}_{2} \mathrm{CO}_{3} 75 \mathrm{mmol} / \mathrm{L}\right.$, glucosa 10 $\mathrm{mmol} / \mathrm{L}$, MOPS-Tris $75 \mathrm{mmol} / \mathrm{L}, \mathrm{pH} 7,4$ ) hasta un hematocrito del $20 \%$. En todas las experiencias se utilizaron eritrocitos obtenidos no más de $6 \mathrm{~h}$ después de la extracción sanguínea. Después de $60 \mathrm{~min}$ de incubación a $37^{\circ} \mathrm{C}$, los eritrocitos se lavaron cuatro veces con una solución de $\mathrm{MgCl}_{2} 115 \mathrm{mmol} / \mathrm{L}$, la última vez centrifugando $(3500 \times \mathrm{g})$ durante $2 \mathrm{~min}$, a $4^{\circ} \mathrm{C}$. Se tomaron cuatro alícuotas para determinar los eflujos de $\mathrm{Li}^{+}$en presencia o ausencia de $\mathrm{Na}^{+}$, la concentración de $\mathrm{Li}+$ intracelular y el hematocrito.

Los eflujos de $\mathrm{Li}+$ se determinaron a partir de la incubación de alícuotas $(1 \mathrm{~mL})$ de la suspensión celular con solución amortiguadora de $\mathrm{NaCl}(\mathrm{NaCl} 150$ $\mathrm{mmol} / \mathrm{L}$, glucosa $10 \mathrm{mmol} / \mathrm{L}$, ouabaína $0.1 \mathrm{mmol} / \mathrm{L}$, MOPS-Tris $10 \mathrm{mmol} / \mathrm{L}, \mathrm{pH} \mathrm{7,4)} \mathrm{durante} 60 \mathrm{~min}$, a $4^{\circ} \mathrm{C}$; o bien con solución amortiguadora carente de $\mathrm{NaCl}$ $\left(\mathrm{MgCl}_{2} 75 \mathrm{mmol} / \mathrm{L}\right.$, glucosa $10 \mathrm{mmol} / \mathrm{L}$, ouabaína 0.1 $\mathrm{mmol} / \mathrm{L}$, sacarosa $85 \mathrm{mmol} / \mathrm{L}$, MOPS-Tris $10 \mathrm{mmol} / \mathrm{L}$, $\mathrm{pH} 7,4)$ durante el mismo tiempo y temperatura. Los eritrocitos se centrifugaron $(3500 \times \mathrm{g}$ ) durante $2 \mathrm{~min}$, a $4^{\circ} \mathrm{C}$, y la concentración de $\mathrm{Li}+$ se determinó en los sobrenadantes mediante espectrofotometría de absorción atómica $\left(I_{670,8^{\prime}}\right.$ Perkin-EImer 460$)$. La velocidad máxima del contratransporte $\mathrm{Na}+-\mathrm{Li}+$ se determinó a partir de la diferencia de concentración de $\mathrm{Li}+$ en los sobrenadantes antes mencionados, considerando que el sistema actúa bajo condiciones de saturación.

Para el análisis estadístico de los datos se calcularon las medias con sus desviaciones estándares de los distintos parámetros. Las diferencias entre las medias se compararon según el análisis de varianza (ANOVA) para datos pareados con distribución nor- mal. Las correlaciones se determinaron empleando el test de regresión lineal de Pearson, calculando también los intervalos con un $95 \%$ de confianza para los coeficientes de regresión. Estos estudios se realizaron con el paquete estadístico GraphPAD InStat (GraphPAD Software).

\section{RESULTADOS Y DISCUSIÓN}

\subsection{Distribución del colesterol en la membrana de eritrocito}

La Figura 4 ilustra los cromatogramas representativos del cambio de masa de colesterol y colestenona de la membrana de eritrocito de sujetos sanos con respecto al tiempo de tratamiento con colesterol oxidasa [la enzima actúa sobre el grupo hidroxilo en posición $3 \beta$ del colesterol, para formar $\Delta^{4}$-colestenona (Lange, 1992)]. Estas cinéticas de oxidación del colesterol confirman estudios previos (Brasaemle et al., 1988), y fueron similares a las encontradas en eritrocito de pacientes con hipertensión esencial (normo- e hipercolesterolémicos), aunque la velocidad del proceso fue significativamente más lenta que la registrada en el grupo control (Figuras 5 y 6 ). En pacientes hipertensos, la súbita oxidación del colesterol (3-12\% del total) indica que el contenido de colesterol en la monocapa externa del eritrocito oscila entre estos valores (Tabla 4). En función de la velocidad de intercambio del colesterol entre ambas monocapas, se aprecia que el resto (colesterol en la monocapa interna) se oxida con mayor lentitud dibujando una cinética hiperbólica (Figura 5). Como consecuencia, la oxidación total del colesterol en eritrocito de pacientes con hipertensión esencial se retrasó $20 \mathrm{~min}$ con respecto a los controles. Estos datos sugieren que el colesterol de la membrana de eritrocito de humanos se encuentra distribuido asimétricamente entre las monocapas externa e interna (Brasaemle et al., 1988; Schroeder et al., 1991b) y por primera vez se demuestra que la monocapa interna del eritrocito de pacientes hipertensos es más rica en colesterol que la de sujetos sanos, indicando que la distribución transmembrana del colesterol puede desempeñar un papel específico en el proceso hipertensivo.

Los tiempos medios ( $50 \%$ del valor) para el descenso de la masa de colesterol en eritrocitos de sujetos sanos y pacientes con hipertensión esencial se expresan en la Tabla 4. Parece evidente que el colesterol difunde más lentamente en la bicapa lipídica del eritrocito de pacientes hipertensos, puesto que se requiere más tiempo para oxidar el $50 \%$ de colesterol total que en los sujetos sanos. Esta dificultad al movimiento de lípidos (colesterol) en o entre cualquiera de las monocapas de una membrana biológica ha sido recientemente asociada a la presencia de dominios ricos en colesterol (Schroeder et al., 1991a; Rothblat 


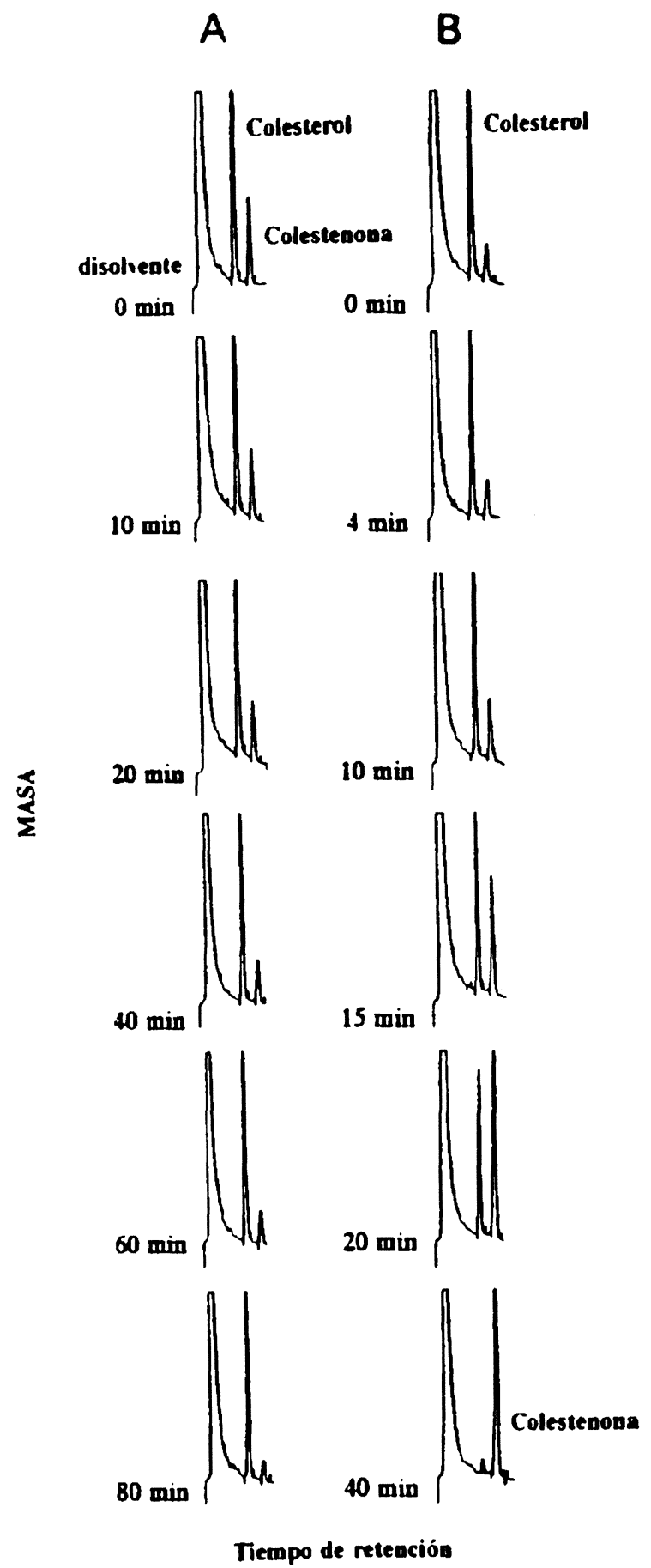

Figura 4

Separación de esteroles (colesterol y colestenona) de la membrana de eritrocito humano tratado breve (A) ó contínuamente (B) con colesterol oxidasa a distintos tiempos $(0 \rightarrow 80 \mathrm{~min})$ de incubación
A
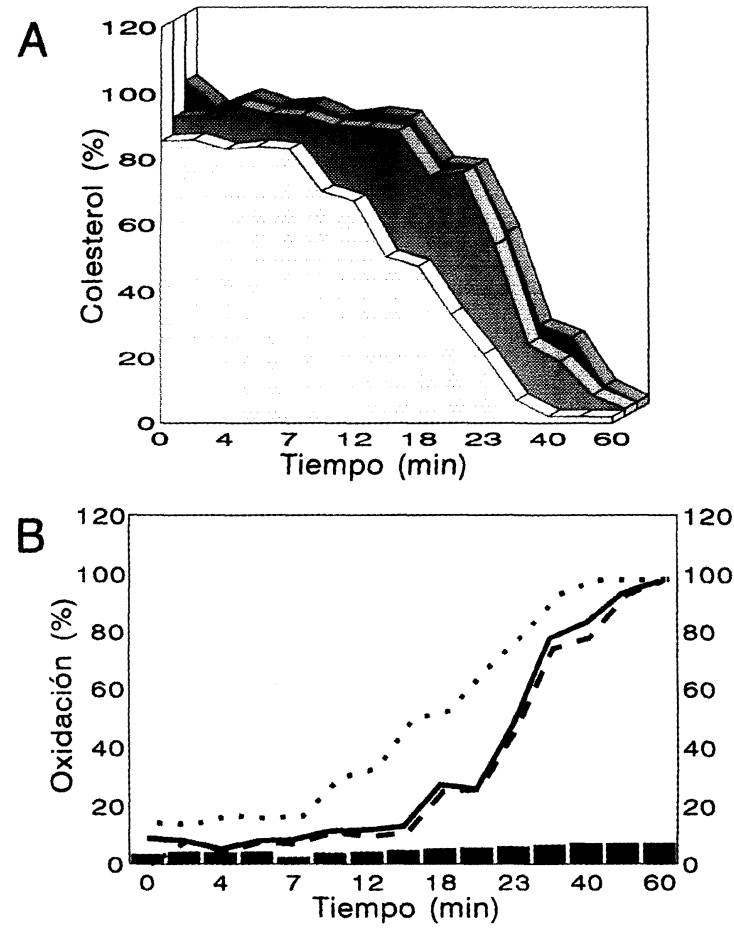

El \% de oxidación se calcula según la relación masa de colesterol/masa total de esteroles (colesterol y colestenona) $(n=12)$.

También se expresa en la gráfica el porcentaje de hemolisis durante el tratamiento con la colesterol oxidasa (barras negras)

Figura 5

Disminución del contenido $(A)$ y oxidación $(B)$ del colesterol de la membrana de eritrocito de sujetos sanos (trama y línea punteadas), y de hipertensos normo- (gris y línea continua) e hipercolesterolémicos (negro y línea discontinua)

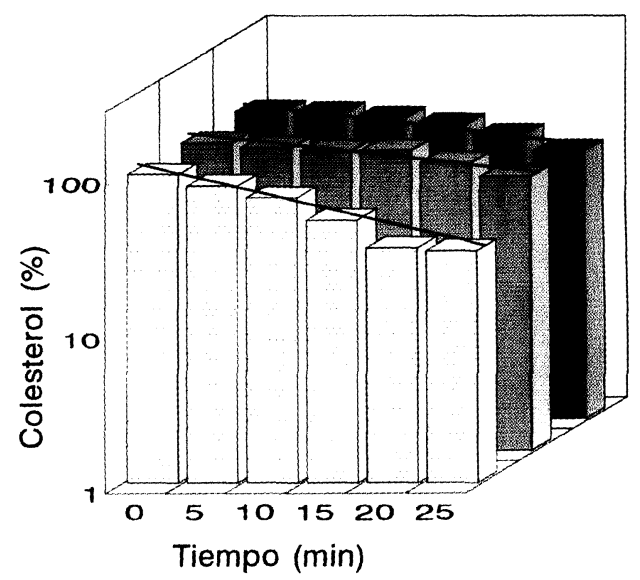

El \% de oxidación se calcula según la relación masa de colesterol/masa total de esteroles (colesterol y colestenona) $(n=12)$

Figura 6

Representación semilogarítmica de la oxidación inicial del colesterol de la membrana de eritrocito de sujetos sanos (trama punteada), y de hipertensos normo- (gris) e hipercolesterolémicos (negro) 
Tabla 4

Colesterol libre en las monocapas y $t^{1} / 2$ para el descenso (por oxidación continua) de la masa de colesterol en la membrana de eritrocito

\begin{tabular}{lccc}
\hline Parámetro & $\begin{array}{c}\text { Sujetos } \\
\text { controles }\end{array}$ & $\begin{array}{c}\text { Pacientes hipertensos } \\
\text { normocolesterolémicos }\end{array}$ & $\begin{array}{c}\text { Pacientes hipertensos } \\
\text { hipercolesterolémicos }\end{array}$ \\
\hline $\begin{array}{l}\text { Colesterol (según tratamiento } \\
\text { continuo con colesterol oxidasa): }\end{array}$ & & & \\
$\quad$ Monocapa externa & $15-17 \%$ & $10-12 \%$ & $9-11 \%$ \\
$\quad$ Monocapa interna & $85-83 \%$ & $90-88 \%$ & $91-89 \%$ \\
$\begin{array}{l}\text { Colesterol (según tratamiento } \\
\text { breve con colesterol oxidasa): }\end{array}$ & & & $3-4 \%$ \\
$\quad \begin{array}{l}\text { Monocapa externa } \\
\text { Monocapa interna }\end{array}$ & $12-14 \%$ & $5-6 \%$ & $97-96 \%$ \\
$t^{1} / 2$ (min) & $88-86 \%$ & $95-94 \%$ & $25,4 \pm 5,6^{\star \star \star}$ \\
\hline
\end{tabular}

Los valores expresan el intervalo o la media desviación estándar $(n=12)$ Valores significativamente diferentes del control: ${ }^{\star \star \star} P<0,001$.

et al., 1992; Liscum y Faust, 1994). Los lípidos en un dominio rico en colesterol están fuertemente empaquetados, son menos proclives a la interacción con proteínas e incluso dificultan la translocación de las mismas. Por lo tanto, esta distribución asimétrica lateral del colesterol en la membrana de eritrocito de pacientes hipertensos puede afectar su fluidez y permeabilidad, así como la función de las proteínas asociadas a esta membrana. En este sentido, es interesante resaltar que la segregación del colesterol de membrana en dominios ricos y pobres resulta esencial para la activación de ciertas proteínas (Schroeder et al., 1991a), en particular de aquellos sistemas de transporte iónico que sufren un proceso de agregación (activación) cuando residen en dominios ricos en colesterol. Este pudiera ser el caso del contratransporte $\mathrm{Na}^{+-} \mathrm{Li}+$, cuya actividad se encuentra aumentada en la hipertensión esencial humana (Canessa et al., 1980; Muriana et al., 1996a,b,c; Ruiz-Gutiérrez et al., 1996).

\subsection{Velocidad de movimiento transmembrana del colesterol en el eritrocito}

Cuando eritrocitos intactos se incuban con $\left[{ }^{3} \mathrm{H}\right]$ colesterol a $4^{\circ} \mathrm{C}$ se produce el marcaje isotópico de la monocapa externa. La incubación subsiguiente a $37^{\circ} \mathrm{C}$ inicia el equilibrio del colesterol entre la monocapa externa e interna mediante un movimiento transmembrana (Brasaemle et al., 1988). El tratamiento con colesterol oxidasa de las células marcadas causa un descenso en la radioactividad específica (dpm $\left[{ }^{3} \mathrm{H}\right]-$ esterol/ $\mu \mathrm{g}$ esterol) de la colestenona con respecto al tiempo, representando la mezcla del «pool» de colesterol radioactivo de la monocapa externa con el «pool» de colesterol no radioactivo, presumiblemente, de la monocapa interna. Es decir, representando la veloci-
A $\quad$ B
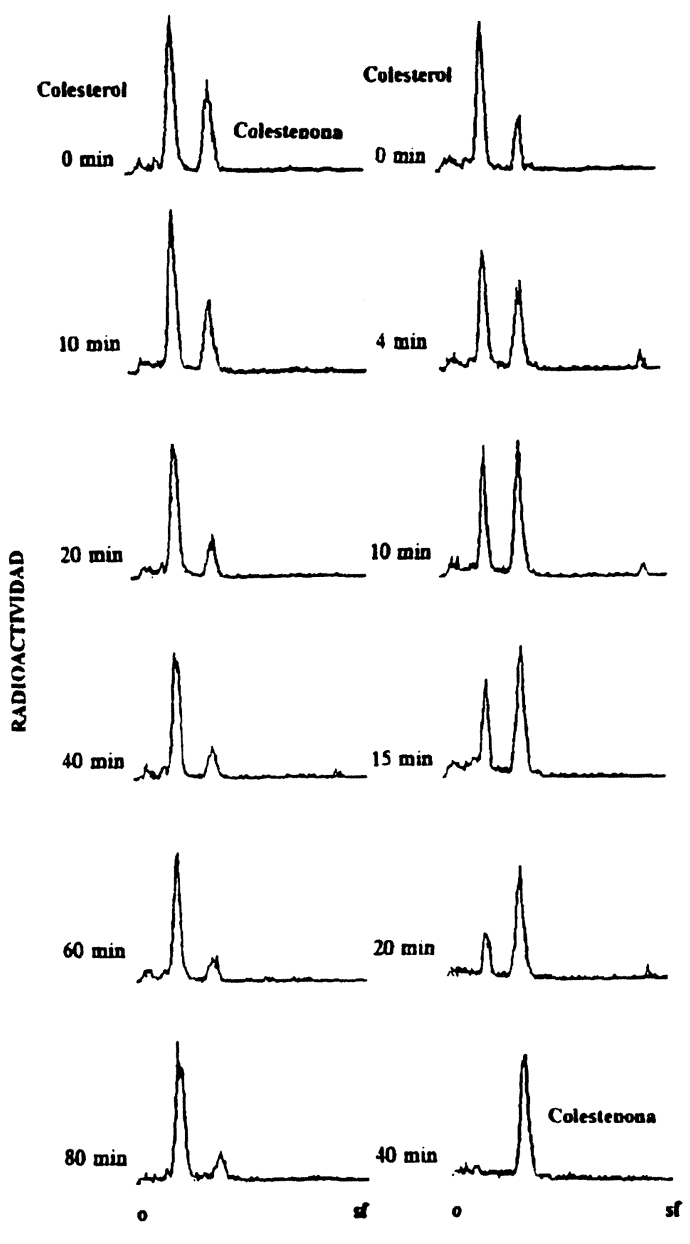

Figura 7

Separación de esteroles radioactivos (colesterol y colestenona) de la membrana de eritrocito humano tratado breve (A) ó contínuamente $(B)$ con colesterol oxidasa a distintos tiempos $(0 \rightarrow 80$ min) de incubación 
dad de movimiento transmembrana del colesterol. La Figura 7 ilustra los cromatogramas característicos del cambio de radioactividad del colesterol y colestenona tras el marcaje de eritrocito de sujetos sanos y posterior tratamiento continuo con colesterol oxidasa. Estas cinéticas de oxidación del colesterol radioactivo confirman estudios previos (Brasaemle et al., 1988; Schroeder et al., 1991b), y fueron similares a las encontradas en eritrocito de pacientes con hipertensión esencial (normo- e hipercolesterolémicos), aunque la velocidad del proceso fue significativamente más lenta que la registrada en el grupo control. Como resultado, la radioactividad específica de la colestenona también decayo más lentamente (Figuras 8 y 9 ). Los tiempos medios (50\% del valor) para el descenso de la

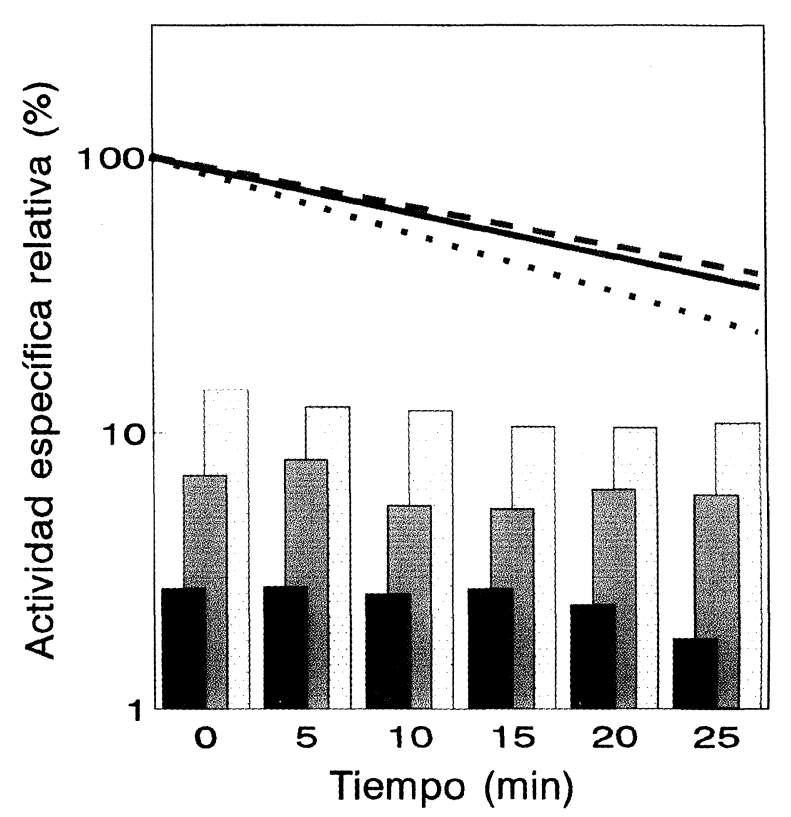

Los valores se expresan como la radioactividad del "pool" de esteroles marcados con tritio $[3 \mathrm{H}] / \mathrm{mg}$ de cada esterol, relativo a la radioactividad específica inicial de la colestenona $(100 \%)(n=12)$

\section{Figura 8}

Cambios en las radioactividades específicas de colesterol (barras) y colestenona (líneas) de la membrana de eritrocito de sujetos sanos (trama y línea punteada), y de hipertensos normo- (gris y línea continua) e hipercolesterolémicos (negro y línea discontinua), tratados brevemente con colesterol oxidasa $(0 \rightarrow 25 \mathrm{~min})$ radioactividad específica de la colestenona en eritrocitos de sujetos sanos y pacientes hipertensos se muestran en la Tabla 5. Esta importante reducción en la velocidad del transporte transmembrana del colesterol en el eritrocito de pacientes con hipertensión esencial puede contribuir aún más a la asimetría transmembrana y lateral del colesterol, ya que la segregación física del colesterol en dominios ricos y pobres es muy dependiente de su velocidad de intercambio en la bicapa lipídica (Schroeder et al., 1991a,b). En este sentido, una velocidad de movimiento baja del colesterol desde la monocapa externa hacia la interna, unido a su distribución asimétrica transmembrana, es indicativo de la existencia de una estructura discreta del colesterol en la membrana caracterizada por la presencia de domi-

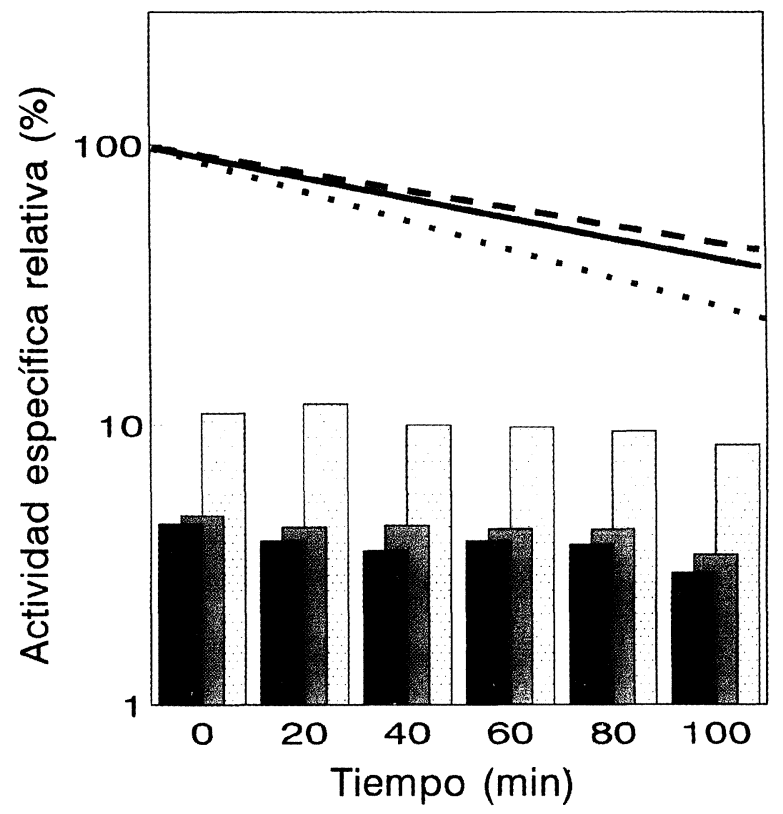

Los valores se expresan como la radioactividad del "pool" de esteroles marcados con tritio $\left[{ }^{3} \mathrm{H}\right] / \mathrm{mg}$ de cada esterol, relativo a la radioactividad especifica inicial de la colestenona $(100 \%)(n=12)$

Figura 9

Cambios en las radioactividades específicas de colesterol (barras) y colestenona (líneas) de la membrana de eritrocito de sujetos sanos (trama y línea punteada), y de hipertensos normo- (gris y línea continua) e hipercolesterolémicos (negro y línea discontinua), tratados continuamente con colesterol oxidasa $(0 \rightarrow 100 \mathrm{~min})$

Tabla 5

Valores de $t^{1} / 2$ para el descenso (por oxidación continua) de la radioactividad específica de la colestenona en la membrana de eritrocito

\begin{tabular}{lccc}
\hline Parámetro & $\begin{array}{c}\text { Sujetos } \\
\text { controles }\end{array}$ & $\begin{array}{c}\text { Pacientes hipertensos } \\
\text { normocolesterolémicos }\end{array}$ & $\begin{array}{l}\text { Pacientes hipertensos } \\
\text { hipercolesterolémicos }\end{array}$ \\
\hline $\mathrm{t}^{1} / 2(\min )$ & $13,9 \pm 2,6$ & $18,3 \pm 3,9^{* *}$ & $20,3 \pm 6,8^{* * *}$
\end{tabular}

Los valores expresan la media desviación estándar $(n=12)$

Valores significativamente diferentes del control: ${ }^{\star \star} P<0,05,{ }^{\star \star \star} P<0,005$. 
nios ricos en colesterol en la monocapa interna (Schroeder et al., 1991a; Rothblat et al., 1992).

Aunque la relación exacta entre los dominios estructurales y cinéticos de colesterol en las membranas biológicas no se conoce, parece que existen diferentes «pools» cinéticos de colesterol que se denominan «pool de colesterol intercambiable» y «pool de colesterol no-intercambiable» y se asocian a los dominios pobres en colesterol y a los dominios ricos en colesterol, respectivamente (Schroeder y Nemecz, 1990; Nemecz y Schroeder, 1988; Nemecz et al., 1988; Schroeder et al., 1991a; Rothblat et al., 1992; Liscum y Faust, 1994). Es decir, puede establecerse una sinonimia entre dominios laterales de colesterol y «pools» cinéticos de colesterol. Estos «pools» cinéticos son generalmente el resultado de la segregación del colesterol en la bicapa lipídica (Rothblat et al., 1992) y, por lo tanto, no sorprende que ello se relacione directamente con los mecanismos de deabsorción del colesterol de la membrana y su intercambio espontáneo (Schroeder et al., 1991a; 1991b; Rothblat et al., 1992; Liscum y Faust, 1994). Según este modelo, puede considerarse que el colesterol de la monocapa externa de la membrana de eritrocito de pacientes hipertensos está constituido esencialmente por un «pool no-intercambiable", puesto que el colesterol difícilmente difunde a través de esta monocapa a la interna, a pesar de estar constituido por dominios pobres en colesterol. Este posible defecto en el comportamiento cinético del colesterol de membrana pudiera tener consecuencias aún por determinar y no por ello poco interesantes, basta mencionar que la capacidad de intercambio lipídico de la monocapa externa modula directamente el flujo intercelular y el transporte reverso del colesterol (Rechl y Miller, 1989; Rothblat et al., 1992). Es, pues, evidente que importantes implicaciones cardiovasculares pueden derivarse según el tamaño del «pool intercambiable y no-intercambiable» de colesterol en la membrana, su velocidad de transferencia, o cualquier combinación de estos tres factores.

Este análisis asume la existencia de un eflujo paralelo en la membrana entre los «pools» de colesterol con cinética rápida («intercambiable») o lenta («nointercambiable») con el aceptor extracelular (Figura 10A). Sin embargo, no hay evidencia experimental que elimine la posibilidad de un intercambio entre los dominios laterales de colesterol (ricos y pobres), donde la velocidad de transferencia del colesterol es relativamente menor a la velocidad de eflujo desde cualquiera de los dominios o «pools» cinéticos (Figura 10B), o bien, donde después de la transferencia del colesterol sólo un dominio o «pool» cinético (el de cinética más rápida) es capaz de participar en el eflujo de colesterol (Figura 10C). El estudio matemático de estos modelos teóricos permite concluir que, en los dos últimos casos ( $B$ y $C$ ), las cinéticas del eflujo de colesterol son bi-exponenciales y más lentas que las obtenidas en el modelo $(A)$, que no asume el intercambio entre dominios (Rothblat et al., 1992).

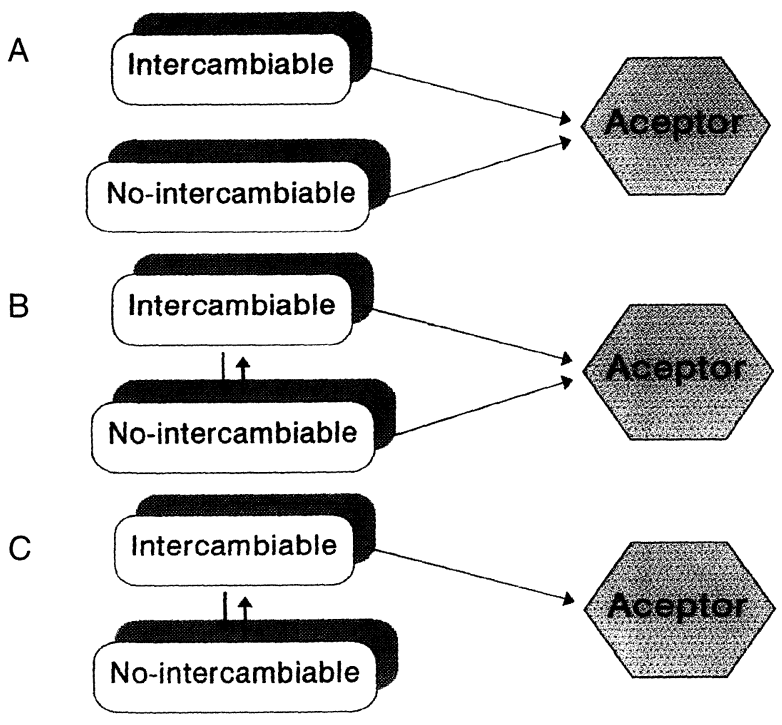

A, eflujo paralelo desde dominios intercambiables (de cinética rápida) y no-intercambiables (de cinética lenta) sin intercambio entre ambos dominios

$B$, eflujo paralelo con intercambio entre dominios

$C$, eflujo desde el dominio intercambiable sin intercambio entre dominios Figura 10

Modelos posibles del movimiento del colesterol desde distintos dominios o «pools» cinéticos de la membrana plasmática hacia aceptores extracelulares

Los valores derivados del tamaño de los «pools» cinéticos y tipo de distribución lateral del colesterol tendrán un impacto evidente sobre la interacción de sus aceptores naturales con la membrana celular y, por lo tanto, en la homeostasis del colesterol. En este sentido, la apolipoproteína (apo) A-I de las lipoproteínas de alta densidad (HDL), el más eficiente aceptor del colesterol celular, parece que interacciona de manera específica con los dominios pobres en colesterol de la membrana (Figura 11) (Rothblat et al., 1992; Liscum y Faust, 1994). Apo A-I se une ligera y transitoriamente mediante sus hélices anfipáticas a los lípidos de membrana, dependiendo su eficiencia de la composición y disposición superficial de la propia apolipoproteína.

\subsection{Correlación de la distribución y velocidad de movimiento transmembrana del colesterol con el contratransporte $\mathrm{Na}+-\mathrm{Li}+$ en el eritrocito}

Distintos estudios sobre la asociación entre los lípidos plasmáticos, que se encuentran en equilibrio dinámico con los lípidos de membrana, y los distintos sistemas de transporte iónico indican que la cantidad de colesterol de membrana se relaciona inversamente con la actividad del contratransporte $\mathrm{Na}^{+-\mathrm{Li}+}$ (Hajem et al., 1990; Lijnen et al., 1992; Carr et al., 1993; Lijnen et 


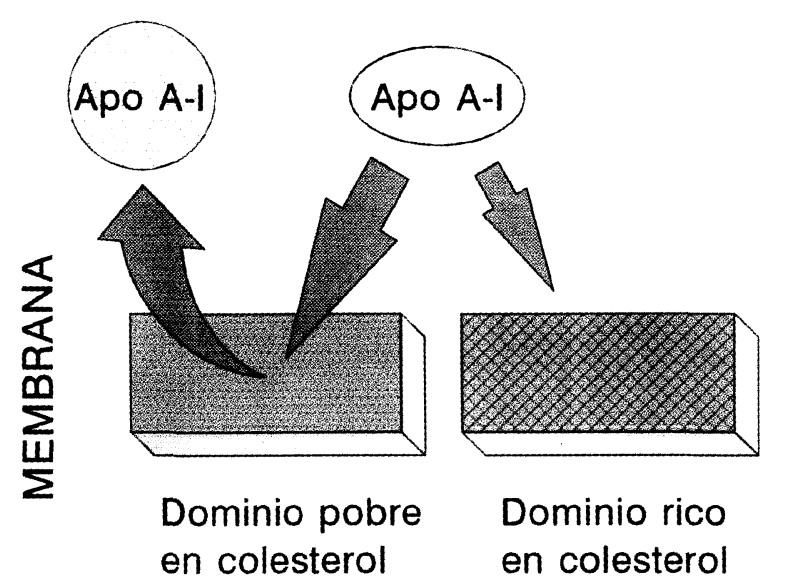

Las moléculas de colesterol se translocan fácilmente desde los dominios pobres en colesterol hacia las moléculas adyacentes de HDL (que contienen apo A-I) («pool» de cinética rápida). Por el contrario, la alta densidad de empaquetamiento en los dominios ricos en colesterol dificulta este tipo de interacción ("pool» de cinética lenta)

\section{Figura 11}

Modelo posible de la interacción de la apolipoproteína (apo) AI con los dominios estructurales de la membrana plasmática

al., 1994). Sin embargo, hoy día se desconoce el mecanismo mediante el cual los lípidos de membrana, incluyendo el colesterol, afectan a este sistema que se considera como marcador genético de la hipertensión esencial (Canessa et al., 1988; Carr et al., 1993). En este sentido, parece posible que el modelo de dominios estructurales y «pools" cinéticos de colesterol en la membrana pueda contribuir a tal comprensión (ver apartados anteriores). Una relación causal entre los distintos parámetros (distribución transmembrana del colesterol, distribución lateral del colesterol, velocidad de movimiento transmembrana del colesterol y actividad del contratransporte $\left.\mathrm{Na}^{+}-\mathrm{Li}^{+}\right)$debe considerarse imprescindible para corroborar o no esta hipótesis.

En primer término, los valores medios de la velocidad máxima del contratransporte $\mathrm{Na}^{+}-\mathrm{Li}+$ en el eritrocito de sujetos sanos y pacientes con hipertensión esencial se expresan en la Tabla 6. En concordancia con otros autores (Canessa et al., 1980; Rutherford et al., 1992; Carr et al., 1993), un incremento en la activi- dad de este sistema de transporte del sodio se asocia con el estado hipertensivo; a mayor actividad, peor pronóstico de la enfermedad.

El análisis de regresión simple demostró que existe una significativa y positiva correlación entre el contratransporte $\mathrm{Na}^{+-} \mathrm{Li}+$ y el tiempo medio para la oxidación (relacionado con la distribución) del colesterol de la membrana de los eritrocitos tanto de los sujetos sanos como de los pacientes con hipertensión esencial (Figura 12). A medida que aumenta el tiempo medio que necesita la colesterol oxidasa para oxidar el $50 \%$ del colesterol a colestenona, entonces aumenta la velocidad máxima del contratransporte $\mathrm{Na}+-\mathrm{Li}+$. Esta resistencia a la oxidación del colesterol en la membrana de eritrocito de pacientes hipertensos es característica de la presencia, ya confirmada, del escaso contenido de colesterol en la monocapa externa y su distribución lateral en dominios pobres (Brasaemle et al., 1988; Schroeder et al., 1991b; Liscum y Faust, 1994; Muriana et al., 1994). La máxima expresión de estos hechos es la reducción de fluidez (aumento de microviscosidad) de la membrana, y la presencia de dominios ricos en colesterol en la monocapa interna con la subsiguiente activación del transportador de sodio (Schroeder et al., 1991a). En la Tabla 7 se indican los coeficientes de correlación de Pearson y los coeficientes de regresión con los respectivos intervalos de confianza $(95 \% \mathrm{CI})$.

Por su parte, también se demostró una significativa y negativa correlación entre el contratransporte $\mathrm{Na}^{+-}$ $\mathrm{Li}^{+}$y el tiempo medio para el descenso de la radioactividad específica de la colestenona (relacionado con el movimiento transmembrana del colesterol) (Figura 13). A medida que aumenta el tiempo medio que se necesita para que el $50 \%$ del colesterol atraviese la membrana del eritrocito, entonces disminuye la velocidad máxima del contratransporte $\mathrm{Na}^{+-} \mathrm{Li}^{+}$. Esta lentitud en el movimiento transmembrana del colesterol en el eritrocito de pacientes hipertensos es característica del enriquecimiento en colesterol, ya confirmado, de la monocapa interna y su distribución lateral en dominios ricos (Brasaemle et al., 1988; Schroeder et al., 1991b; Liscum y Faust, 1994; Muriana et al., 1995). Considerando los datos en su conjunto: una mayor lentitud en el movimiento transmembrana del colesterol en los grupos de pacientes con hipertensión esencial se asocia con un aumento de la velocidad máxima

Tabla 6

Valores de la velocidad máxima del contratransporte $\mathrm{Na}^{+-} \mathrm{Li}+$ en el eritrocito

\begin{tabular}{lccc}
\hline Parámetro & $\begin{array}{c}\text { Sujetos } \\
\text { controles }\end{array}$ & $\begin{array}{c}\text { Pacientes hipertensos } \\
\text { normocolesterolémicos }\end{array}$ & $\begin{array}{c}\text { Pacientes hipertensos } \\
\text { hipercolesterolémicos }\end{array}$ \\
\hline Vmáx $(\mathrm{mmol} / \mathrm{h} / \mathrm{L}$ de células) & $0,262 \pm 0,081$ & $0,304 \pm 0,037$ & $0,410 \pm 0,094^{\star \star \star}$ \\
\hline
\end{tabular}

Los valores expresan la mediatdesviación estándar $(n=12)$

Valores significativamente diferentes del control: ${ }^{\star \star \star} P<0,005$ 


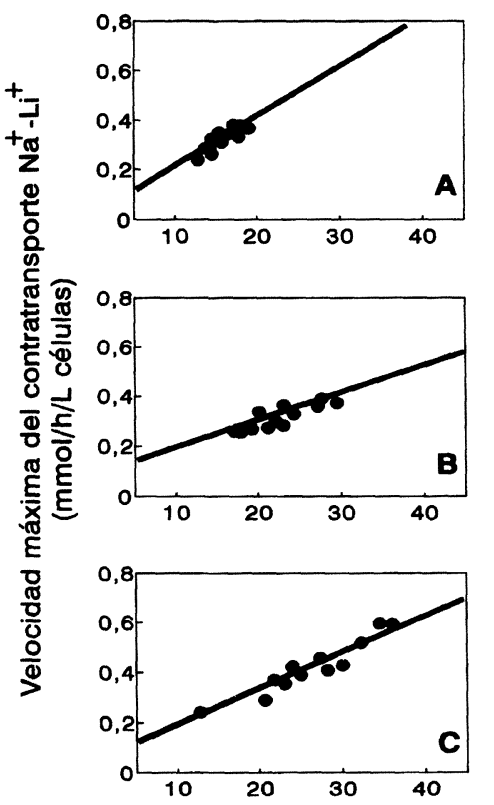

t $1 / 2$ oxidación colesterol (min)

Los valores de cada grupo $(n=12)$ cumplen las ecuaciones lineales siguientes: $y=0,029 x-0,198, r=0,94, P<0,0001, R^{2}=88,7 \%$ (sujetos sanos); $y=0,015 x-0,019$, $r=0,93, P<0,0001, R^{2}=87,5 \%$ (pacientes hipertensos normocolesterolémicos); $y=0,019 x-0,069, r=0,93 P<0,0001, R^{2}=86,8 \%$ (pacientes hipertensos hipercolesterolémicos)

Figura 12

Relación entre el contratransporte $\mathrm{Na}^{+-} \mathrm{Li}^{+}$y $\mathrm{t} 1 / 2$ para el descenso del contenido de colesterol (por oxidación continua) de la membrana de eritrocito de sujetos sanos (A), y de hipertensos normo- (B) e hipercolesterolémicos (C)

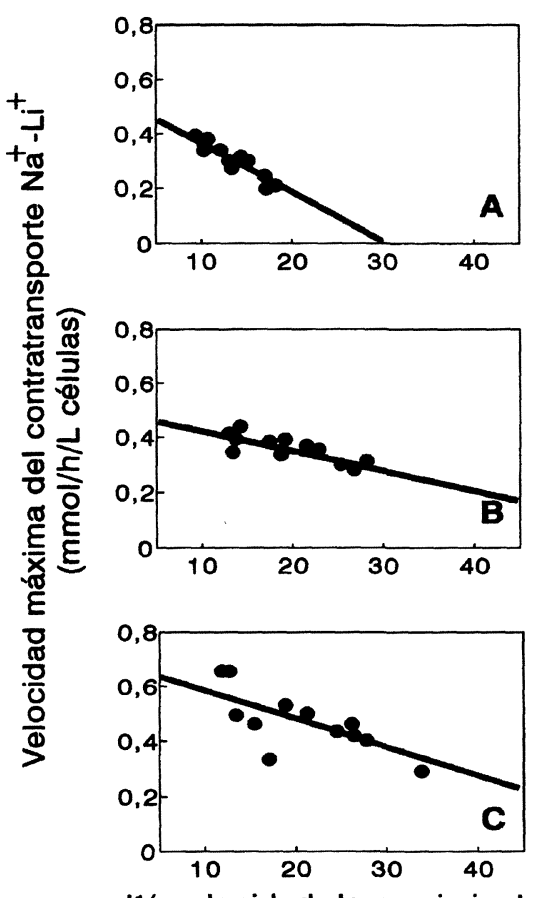

$t 1 / 2$ velocidad de movimiento colesterol (min)

Los valores de cada grupo $(n=12)$ cumplen las ecuaciones lineales siguientes: $y=-0,015 x+0,472, r=-0,90, P<0,0001, R^{2}=80,7 \%$ (sujetos sanos); $y=-0,008 x+0,451$, $r=-0,82, \quad P<0,005, R^{2}=67,1 \%$ (pacientes hipertensos normocolesterolémicos): $y=-0,010 x+0,613, r=-0,77, P<0,005, R^{2}=58,7 \%$ (pacientes hipertensos hipercolesterolémicos

\section{Figura 13}

Relación entre el contratransporte $\mathrm{Na}^{+}-\mathrm{Li}^{+}$y $\mathrm{t1} / 2$ para el descenso (por oxidación continua) de la radioactividad específica de la colestenona (velocidad de movimiento del colesterol) de la membrana de eritrocito de sujetos sanos (A), y de hipertensos normo- (B) e hipercolesterolémicos (C)

Tabla 7

Correlaciones lineales $(P<0,001 ; n=12)$ de la velocidad máxima del contratransporte $\mathrm{Na}^{+}-\mathrm{Li}+$ con los valores $\mathrm{t}^{1} / 2$ para el descenso (por oxidación continua) de la masa del colesterol en la membrana de eritrocito

\begin{tabular}{lccc}
\hline Parámetro & $\begin{array}{c}\text { Sujetos } \\
\text { controles }\end{array}$ & $\begin{array}{c}\text { Pacientes hipertensos } \\
\text { normocolesterolémicos }\end{array}$ & $\begin{array}{c}\text { Pacientes hipertensos } \\
\text { hipercolesterolémicos }\end{array}$ \\
\hline Coeficiente de correlación $(r)$ & 0,9419 & 0,9352 & 0,9315 \\
Coeficiente de regresión $(b)$ & 0,0298 & 0,0149 & 0,0189 \\
$95 \% \mathrm{Cl}$ para $b$ & 0,0223 a 0,0372 & 0,0109 a 0,0189 & 0,0137 a 0,0240 \\
\hline
\end{tabular}


del contratransporte $\mathrm{Na}^{+}-\mathrm{Li}+$ (Figura 14), es decir, existe una correlación positiva entre ambos parámetros, en concordancia con los resultados de distribución del colesterol. La interpretación de esta aparente contradicción puede hallarse en las condiciones preliminares de la bicapa lipídica de los eritrocitos de las personas que participaron en el presente estudio. Como se ha demostrado, las alteraciones concomitantes o no de los dominios estructurales y cinéticos de colesterol en la membrana de eritrocito son inherentes a la propia enfermedad. Por lo tanto, las diferencias encontradas entre los valores de velocidad de movimiento transmembrana y de actividad del contratransporte $\mathrm{Na}^{+}-\mathrm{Li}^{+}$, cuando se compara el grupo control con los grupos de hipertensos, pueden explicarse en estos términos. Del análisis individual de los datos (es decir, de los componentes de cada grupo), la mayor lentitud en el movimiento transmembrana del colesterol puede significar una disminución de la capacidad de difusión lipídica del colesterol en la monocapa interna, de agregación de las proteínas que se encuentran en la membrana y, por lo tanto, de la formación de las especies activas del contratransporte $\mathrm{Na}^{+}-\mathrm{Li}^{+}$(Schroeder et al., 1991a).

Los correspondientes coeficientes de correlación, de regresión y los intervalos de confianza se expresan en la Tabla 8.

Estos resultados son concluyentes, existe una asociación causal entre un indicador genético de la hipertensión esencial (contratransporte $\mathrm{Na}^{+}-\mathrm{Li}^{+}$) y los parámetros relacionados con la definición de las características estructurales y cinéticas del colesterol en la membrana de eritrocito humano.

\section{CONCLUSIONES}

Por primera vez se han determinado la distribución transmembrana-lateral del colesterol y su velocidad de movimiento transmembrana en eritrocito de pacientes con hipertensión esencial, y se ha comprobado que estos parámetros se encuentran alterados en la enfer-
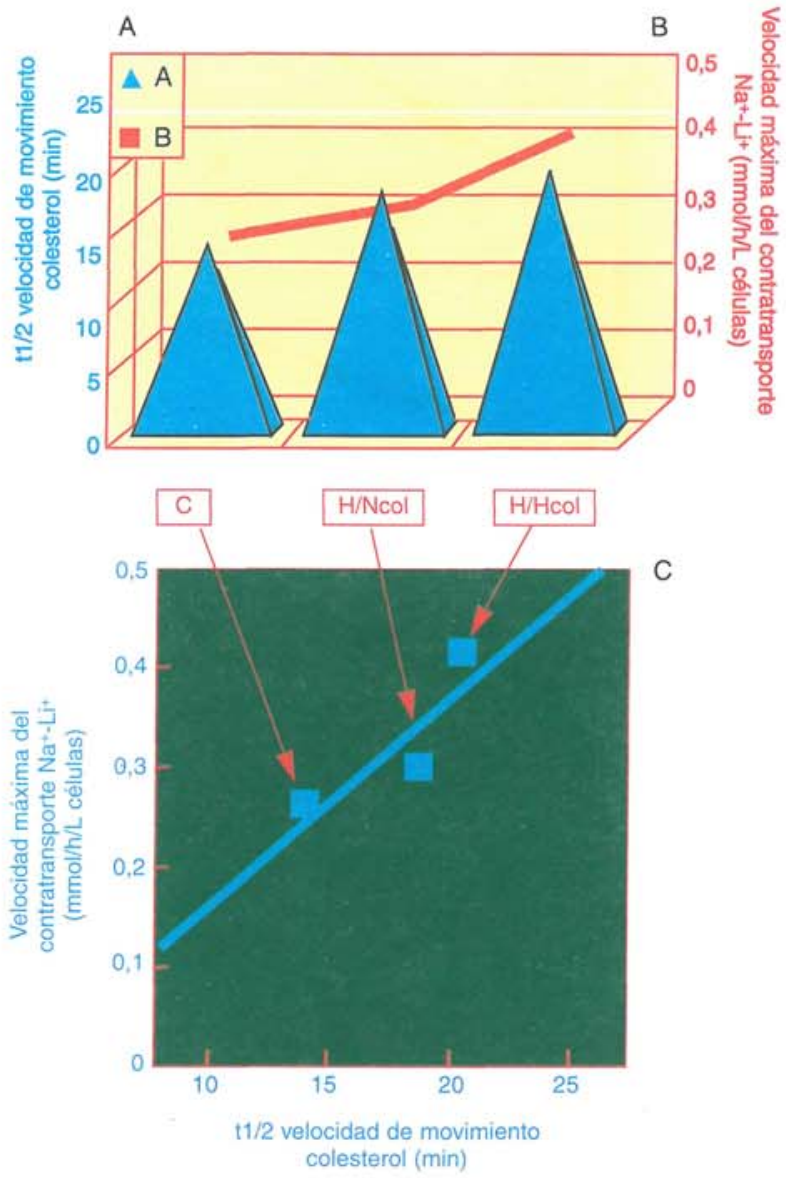

Figura 14

t1/2 para el descenso (por oxidación continua) de la radioactividad específica de la colestenona (A) y velocidad máxima del contratransporte $\mathrm{Na}^{+}-\mathrm{Li}^{+}(\mathrm{B})$ en la membrana de eritrocito de sujetos sanos (control), y de hipertensos normo- (HT/Ncol) e hipercolesterolémicos (HT/Hcol). Correlación entre ambos parámetros $(\mathrm{C})[r=0,8913, P=0,29]$

Tabla 8

Correlaciones lineales $(P<0,005 ; n=12)$ de la velocidad máxima del contratransporte

$\mathrm{Na}^{+-} \mathrm{Li}+$ con los valores $\mathrm{t}^{1} / 2$ para el descenso (por oxidación continua) de la radioactividad específica de la colestenona en la membrana de eritrocito

\begin{tabular}{lccc}
\hline Parámetro & $\begin{array}{c}\text { Sujetos } \\
\text { controles }\end{array}$ & $\begin{array}{c}\text { Pacientes hipertensos } \\
\text { normocolesterolémicos }\end{array}$ & $\begin{array}{c}\text { Pacientes hipertensos } \\
\text { hipercolesterolémicos }\end{array}$ \\
\hline Coeficiente de correlación $(r)$ & $-0,8983$ & $-0,8191$ & $-0,7664$ \\
Coeficiente de regresión $(b)$ & $-0,0152$ & $-0,0081$ & $-0,0102$ \\
$95 \%$ Cl para $b$ & $-0,0205$ a $-0,0099$ & $-0,0119$ a $-0,0041$ & $-0,0163$ a $-0,0042$ \\
\hline
\end{tabular}

$\mathrm{Cl}$ intervalo de confianza 
medad. El resultado de estas modificaciones sugiere la existencia de un "pool» cinético de colesterol «nointercambiable» en la monocapa externa de la membrana de eritrocito de pacientes hipertensos, con un efecto potencial sobre los procesos de intercambio intercelular y transporte reverso del colesterol.

Otro hecho sin precedentes, que pudiera contribuir al entendimiento de la patogénesis de la hipertensión esencial, ha sido la demostración de una relación causal de los dominios estructurales y cinéticos del colesterol de membrana con el contratransporte $\mathrm{Na}^{+}-\mathrm{Li}+$. La novedad de estos resultados también radica en el modelo experimental que se propone para explicar la activación de este sistema de transporte.

Por lo tanto, es razonable afirmar que, en el caso de comprobarse un papel patogénico «activo» en la hipertensión esencial de la distribución y movimiento transmembrana del colesterol, la regulación de estos parámetros pudiera constituir el futuro de nuevas generaciones de medicamentos para el tratamiento de la hipertensión y, en su caso, de las hiperlipidemias. Más importante, si la ingesta de aceite de oliva virgen $u$ otros aceites vegetales es suficiente para normalizar la estructura y funcionalidad de las membranas celulares (en pacientes con hipertensión esencial u otras enfermedades modificables por la dieta y asociadas al metabolismo lipídico), tendríamos la posibilidad de estudiar los componentes de estos aceites con una actividad biológica de interés. Sería posible una más profunda caracterización del aceite de oliva virgen destinada a mejorar su calidad, producción y uso en la prevención y/o tratamiento de ciertas enfermedades. Por último, también se potenciaría su consumo.

\section{AGRADECIMIENTOS}

A la Comisión Interministerial de Ciencia y Tecnología (CICYT) por el apoyo económico a este estudio mediante los Proyectos ALI 92-0881 y ALI 950073. También a todos los participantes directos en los ensayos clínicos, incluyendo al personal técnico e investigador.

\section{BIBLIOGRAFÍA}

Barenholz, Y. - «Sphingomyelin-lecithin balance in membrane composition, structure, and function relationships".- In: Shinitzky M., ed. Physiology of Membrane Fluidity. Boca Raton, F. L.: CRC Press, 1984: 131-173.

Brasaemle, D. L., Robertson, A. D., Attie A. D. - «Transbilayer movement of cholesterol in the human erythrocyte membrane".- J. Lipid Res. 1988, 29: 481-489.

Canessa, M., Adragna, N., Salomon, H. S., et al:- «Increased sodium-lithium countertransport in red cells of patients with untreated essential hypertension».- N. Engl. J. Med.1980, 302: 772-776.
Canessa, M., Morgan, K., Semplicini, A. - "Genetic differences in lithium-sodium exchange and regulation of the sodium-hydrogen exchanger in essential hypertension".J. Cardiovasc. Pharmacol. 1988,12: S92-S98.

Canessa, M., Morgan, K., Goldszer, R., et al.: - "Kinetic abnormalities of the red blood cell sodium-proton exchange in hypertensive patients".- Hypertension 1991, 17: 340-348.

Carr, P., Taub, N. A., Watts, G. F., Poston, L. -«Human lymphocyte sodium-hydrogen exchange».- Hypertension 1993, 21: 344-352.

Carr, S. J., Thomas, L. N., Laker, M. F., Wilkinson, R. -«Elevated sodium-lithium countertransport: A familial marker of hyperlipidaemia and hypertension».- $J$. Hypertens. 1990, 8: 139-146.

Cooper, R. S., Shamsi, N., Katz, S. - Intracellular calcium and sodium in hypertensive patients".- Hypertension 1987, 9: 224-229.

Corrocher, R., Pagnan, A., Ambrosio, G. B., et al.: - «Effects induced by olive oil-rich diet on erythrocytes membrane lipids and sodium-potassium transports in postmenopausal hypertensive women».- J. Endrocrinol. Invest. 1992, 15: 369-376.

David-Dufilho, M., Astaire, C., Pernollet, M. G., et al.: - "Control of the erythrocyte free calcium concentration in essential hypertension».- Hypertension 1992, 19: 167174.

Devaux, P. F. -«Phospholipid filipases».- FEBS Lett 1988, 234: 8-12.

Dominiczak, A. F., Bohr, D. F. - The primary of membrane microviscosity in genetic hypertension".- $A m$. J. Hypertens. 1991, 4: 963-969.

Doria, A., Fioretto, P., Avogaro, A., et al.: - «Insulin resistance is associated with high sodium-lithium countertransport in essential hypertension".- Am. J. Physiol. 1991, 261: E684-E691.

Engler, M. M., Engler, M. B., Erickson, S. K., Paul, S. M. - «Dietary gamma-linolenic acid lowers blood pressure and alters aortic reactivity and cholesterol metabolism in hypertension".- J. Hypertens. 1992, 10: 1197-1204.

Garay, R. P., Adragna, N., Canessa, M., Tosteson, D. C. - "Outward sodium and potassium cotransport in human red cells".- J. Membrane Biol. 1981, 62: 169-174.

Hajem, S., Moreau, T., Hannaert, P., et al.: - «Erythrocyte cation transport systems and plasma lipids in a general male population».- J. Hypertens. 1990, 8: 891-896.

Heagerty, A. M., Ollerenshaw, J. D., Robertson, D. I., et al.: - «Influence of dietary linoleic acid on leucocyte sodium transport and blood pressure".- Br. Med. J. 1986, 293: 295-297.

Insel, P. A., Motulsky, H. J. - «A hypothesis linking intracellular sodium, membrane receptors, and hypertension".Life Sci. 1984, 34: 1009-1013.

Lange, Y. - «Tracking cell cholesterol with cholesterol oxidase».- J. Lipid Res. 1992, 33: 315-321.

Lijnen, P., Fagard, R., Staessen, J., et al.: -«Erythrocyte membrane lipids and cationic transport systems in men".- J. Hypertens. 1992, 10: 1205-1211.

Lijnen, P., Petrov, V., Amery, A. -«Relationship between erythrocyte cation transport systems and membrane and plasma lipids in healthy men».- Am. J. Med. Sci. 1994, 307: S146-S149.

Liscum, L., Faust, J. R. - «Compartmentation of cholesterol within the cell».- Curr. Opin. Lipidol. 1994, 5: 221-226.

Mattiasson, J., Berntorp, K., Lindgärde, F. - «Sodium-lithium countertransport in relation to insulin sensitivity and blood pressure in women".- J. Hypertens. 1991, 6: S463. 
Mclver, D. H., McNally, P. G., Ollerenshaw, J. D., et al.: - «The effect of short chain fatty acid supplementation on membrane electrolyte transport and blood pressure".- $J$. Hum. Hypertens. 1990, 4: 485-490.

Muriana, F. J. G., García-Donas, M. A., Villar, J., RuizGutiérrez, V. - "Distribution of erythrocyte membrane cholesterol in human essential hypertension".- J. Hypertens. 1994, 12: 1383-1386.

Muriana, F. J. G., Villar, J., Ruiz-Gutiérrez, V. -«Erythrocyte membrane cholesterol distribution in patients with untreated essential hypertension: correlation with sodium-lithium countertransport».- J. Hypertens. 1996a, 14: 443446.

Muriana, F. J. G., Ruiz-Gutiérrez, V., Guerrero, A., et al.: - "Olive oil normalizes the altered distribution of membrane cholesterol and sodium-lithium countertransport activity in erythrocyte of hypertensive patients".- J. Nutr. Biochem. 1996b, (en prensa).

Muriana, F. J. G., Montilla, C., Villar, J., Ruiz-Gutiérrez, V. - "Transbilayer movement of erythrocyte membrane cholesterol in human essential hypertension".- J. Hypertens. 1995, 13: 619-623.

Muriana, F. J. G., Montilla, C., Stiefel, P., et al.: - «The rate of transbilayer movement of erythrocyte membrane cholesterol is correlated with sodium-lithium countertransport».- Life Sci. 1996c, 59: 1945-1949.

Nemecz, G., Fontaine, R. N., Schroeder, F. - «A fluorescence and radiolabel study of sterol exchange between membranes".- Biochim. Biophys. Acta. 1988, 943: 511-521.

Nemecz, G., Schroeder, F. -«Membrane cholesterol heterogeneity and exchange studied using dehydroergosterol".- Biochemistry 1988, 27: 7740-7749.

Pagnan, A., Corrocher, R., Ambrosio, G. B., et al.: - «Effects of an olive-oil-rich diet on erythrocyte membrane lipid composition and cation transport systems".- Clin. Sci. 1989, 76: 87-93.

Postnov, Y. V. - «An approach to the cell membrane alteration in hypertension».- Hypertension 1990, 15: 332-337.

Poston, L. -«Endogenous sodium pump inhibitors: A role in essential hypertension?».- Clin. Sci. 1987, 72: 647-655.

Rechl, D., Miller, N. E. -«Pathophysiology of reverse cholesterol transport».- Arteriosclerosis 1989, 9: 785-797.

Ronquist, G., Frithz, G., Gunnarsson, K., Arvidson G. - "Decreased erythrocyte cholesterol/phopholipid ratio in untreated patients with essential hypertension".- J. Intern. Med. 1992, 232: 247-251.
Rothblat, G. H., Mahlberg, F. H., Johnson, W. J., Phillips, M. C. - Apolipoproteins, membrane cholesterol domains, and the regulation of cholesterol efflux".- J. Lipid Res. 1992, 33: 1091-1097.

Ruiz-Gutiérrez, V., Muriana, F. J. G., Guerrero, A., et al: - OOlive oil and high-oleic sunflower oil on plasma lipids, erythrocyte membrane lipids and blood pressure of healthy women".- Nutr. Res. 1997, (en revision).

Rutherford, P. A., Thomas, T. H., Wilkinson, R. - Erythrocyte sodium-lithium countertransport: clinically useful, pathophysiologically instructive or just phenomenology?".Clin. Sci. 1992, 82: 341-352.

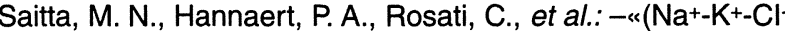
) cotransport function and dysfunction in different forms of primary hypertension».- Am. J. Hypertens. 1988, 1: 6063.

Sandhagen, B., Fritz, G., Waern, U., Ronquist, G. - «Increased whole blood viscosity combined with decreased erythrocyte fluidity in untreated patients with essential hypertension".- J. Interns. Med. 1990, 228: 623-626.

Schroeder, F., Jefferson, J. R., Kier, A. B., et al.: - «Membrane cholesterol dynamics: cholesterol domains and kinetic pools».- Proc. Soc. Exp. Biol. Med. 1991a, 196: 235-252.

Schroeder, F., Nemecz, G. - «Transmembrane cholesterol distribution".- In Esfahani M., Swaney J., eds. Advances in Cholesterol Research. West Caldwell, N. J.: Telford Press, 1990: 47-87.

Schroeder, F., Nemecz, G., Wood, W. G., et al.: - «Transmembrane distribution of sterol in the human erythrocyte".- Biochim. Biophys. Acta 1991b, 1066:183192.

Shouffani, A., Kanner, B. I. - «Cholesterol is required for the reconstitution of the sodium and chloride-coupled, gamma-aminobutyric acid transporter from rat brain". $-J$ Biol. Chem. 1990, 265: 6002-6008.

Straznicky, N. S., Louis, W. J., McGrade, P., Howes, L. G. - «The effects of dietary lipid modification on blood pressure, cardiovascular reactivity and sympathetic activity in man».- J. Hypertens. 1993, 11: 427-437.

Tocanne, J. F., Dupou-Cezanne, L., López, A., Tournier, J. F. - Lipid lateral diffusion and membrane organization».FEBS Lett. 1989, 257: 10-16.

Villar, J., Muñiz, O., Stiefel, P., et al.: - "The influence of hyperinsulinemia in the lipid profile of hypertensive patients".Med. Clin. (Barc.) 1994, 76: 537-540. 